Research Article

\title{
Chemical Compounds Identification and Antioxidant and Calcium Oxalate Anticrystallization Activities of Punica granatum L.
}

\author{
Rabie Kachkoul (D), ${ }^{1,2}$ Tarik Squalli Houssaini, ${ }^{3,4}$ Mohamed Mohim (D), \\ Radouane El Habbani, ${ }^{1}$ and Anissa Lahrichi ${ }^{1}$ \\ ${ }^{1}$ Laboratory of Biochemistry, Faculty of Medicine and Pharmacy, Sidi Mohammed Ben Abdellah University, BP 1893, Km 22, \\ Road of Sidi Harazem, Fez, Morocco \\ ${ }^{2}$ Faculty of Science and Technology, Sidi Mohammed Ben Abdellah University, BP 2202, Road of Imouzzer, Fez, Morocco \\ ${ }^{3}$ Laboratory of Molecular Bases in Human Pathology and Therapeutic Tools, Faculty of Medicine and Pharmacy, \\ Sidi Mohammed Ben Abdellah University, BP 1893, Km 22, Road of Sidi Harazem, Fez, Morocco \\ ${ }^{4}$ Department of Nephrology, University of Hospital Hassan II, BP 1835, Atlas, Road of Sidi Harazem, Fez, Morocco
}

Correspondence should be addressed to Rabie Kachkoul; rabie.kachkoul@usmba.ac.ma

Received 13 October 2019; Revised 19 January 2020; Accepted 3 February 2020; Published 24 February 2020

Academic Editor: Francisco Solano

Copyright (c) 2020 Rabie Kachkoul et al. This is an open access article distributed under the Creative Commons Attribution License, which permits unrestricted use, distribution, and reproduction in any medium, provided the original work is properly cited.

\begin{abstract}
The plant Punica granatum L. has several biological activities and a great curative and preventive power against chronic diseases. For this purpose, the objective of this work is to valorize the fruit peel of this plant in the field of phytomedicine, by quantifying and identifying its bioactive compounds and by evaluating their antioxidant and anticrystallization activities against calcium oxalate. This comparative study has been carried out by hydroalcoholic extract (E.PG) and infusion (I.PG) of the plant. The quantification of the phenolic compounds has been performed by spectrophotometric methods, and the chemical species identification has been performed by UPLC-PDA-ESI-MS. Moreover, the examination of the antioxidant activity has been executed by both methods of DPPH and FRAP. The crystallization inhibition has been studied in vitro by the turbidimetric model. The characterization of the synthesized crystals has been accomplished by microscopic observation and by Fourier Transform Infrared Spectroscopy. The results found show the comparable importance of the two plant extracts in the elimination of free radicals; the values of the half maximal inhibitory concentration " $\mathrm{IC}_{50}$ " obtained are in the order of $60.87 \pm 0.27$ and $59.91 \pm 0.83 \mu \mathrm{g} / \mathrm{mL}$ by the DPPH method and in the order of $42.17 \pm 7.46$ and $79.77 \pm 6.91 \mu \mathrm{g} / \mathrm{mL}$ by the FRAP method, for both E.PG and I.PG, respectively. Furthermore, the inhibition percentages of calcium oxalate crystallization are in the range of $98.11 \pm 0.17$ and $98.22 \pm 0.71 \%$ against the nucleation and in the order of $88.98 \pm 0.98$ and $88.78 \pm 2.48 \%$ against the aggregation, for E.PG and I.PG, respectively. These results prove the richness of the plant in bioactive compounds, offering an antioxidant and anticrystallization capacity; therefore, it can be used in the treatment and/or the prevention of stone formation.
\end{abstract}

\section{Introduction}

Urolithiasis is a severe pathology characterized by the formation of stones in the kidneys or in the urinary tract and can lead to kidney failure. It affects 4 to $20 \%$ of the population and the recurrence rate was estimated at $50 \%$ during the first 5 years with the predominance of calcium oxalate [1-6]. The crystals of the latter are found mainly in three different forms, calcium oxalate monohydrate $(\mathrm{COM})$ or Whewellite, calcium oxalate dihydrate (COD) or Weddellite, and calcium oxalate trihydrate (COT) [7-9]. The "COM" is the most thermodynamically stable form and has a high affinity for renal tubular cells; consequently, it is the initiator of stone formation in the kidney $[10,11]$.

The process of calcium oxalate crystallization begins with increased urinary supersaturation [12], followed by 
nucleation and aggregation [12-14]. The crystals develop and accumulate with other crystals in solution and are finally retained and accumulated in the kidney [14-16]. The damage to the kidney membrane induced by oxalate is mediated by free radicals [17]; consequently it promotes the crystalline retention at the renal papillary surface, as well as the crystal nucleation at lower levels of supersaturation [18]. In addition, the antioxidants contribute importantly on the prevention of stone formation by maintaining the normal physiological concentration of the free radicals and provide the protection against the oxidative damage of endothelial cells [17].

The plant Punica granatum L. "Pomegranate" belongs to the family of Punicaceae, considered to be a Middle East descendent. It extends throughout the Mediterranean, China, India, Europe, North America, and South America [19-21]. It is a small tree or a large shrub, with obovate deciduous leaves with bright red flowers. The fruits are berries delimited by a pericarp, containing many seeds surrounded by a translucent juice bag called arils attached to the inside of the fruit by the mesocarp [19, 22-24]. Regarding the bioactive compounds of the plant, pomegranate fruit remains a more diverse source of bioactive phenolic compounds, particularly phenolic acids, flavonoids, anthocyanins, and tannins [22, 25-28]. The saturated and unsaturated fatty acids are also present mainly in the seeds $[29,30]$. This richness proves the curative and preventive potential of the plant against the chronic diseases, as well as the multiple biological activities, such as antimicrobial, antioxidant, antidiarrhea, antitumor, antimetastasis, antiproliferative, anti-inflammatory, and antinociceptive ones. Moreover, it has an effect against brain's oxidative damage and prevents giardiasis and obesity [30-40]. In this context, the purpose of this study is the evaluation of the anticrystallization effect of calcium oxalate monohydrate and the antioxidant effect of the two extracts made from Punica granatum L. fruit peels (I.PG and E.PG) in addition to the demonstration of the relationship between these two activities, then dosing and identifying their chemical compounds using the colorimetric methods and Ultra Performance Liquid chromatography-photodiode-array-electrospray ionization-mass spectrometry (UPLC-PDA-ESI-MS).

\section{Materials and Methods}

\subsection{Extraction}

2.1.1. Hydroethanolic Extract. The fruits of Punica granatum $\mathrm{L}$ have been harvested from the Taounate region (located in the north of Morocco, $92 \mathrm{~km}$ from the city of Fez, $34^{\circ} 32^{\prime} 09^{\prime \prime} \mathrm{N}, 4^{\circ} 38^{\prime} 24^{\prime \prime} \mathrm{W}$ ), in November 2017. Taxonomic identification was performed by Prof. A. Bari, Department of Biology, Faculty of Sciences Dhar El-Mahraz, Sidi Mohammed Ben Abdellah University, Fez, Morocco. The peels have been dried in the dark at a room temperature of $25^{\circ} \mathrm{C}$ and crushed to obtain a fine fraction. For the preparation of the hydroalcoholic extract (E.PG) we followed the method of Kachkoul et al. [41], which consists in introducing $20 \mathrm{~g}$ of powder in the cellulosic cartridge; the latter is inserted into the extractor of the Soxhlet assembly surmounted by a refrigerant and $170 \mathrm{~mL}$ of $\mathrm{n}$-hexane in the mounting flask, following boiling for $4 \mathrm{~h}$ at $65^{\circ} \mathrm{C}$. The lipid extract is then recovered by removing the solvent using a rotary evaporator under vacuum $[42,43]$. Then, a second hydroalcoholic extraction was carried out on the defatted mark in the same way as the first extraction using a mixture of ethanol/distilled water $(80: 20 \mathrm{v}: \mathrm{v})$ for $4 \mathrm{~h}$; the elimination of ethanol and water is also done using the Rotavapor.

2.1.2. Infusion. The infusion was prepared by the method described by Jiménez-Zamora et al. [44] with some modifications. Briefly, $2 \mathrm{~g}$ of the fruit peel powder placed in $100 \mathrm{~mL}$ of boiling distilled water is allowed to be infused for $30 \mathrm{~min}$ and then filtered using a filter paper with a diameter of $1.6 \mu \mathrm{m}$. The infusion (I.PG) was concentrated by Rotavapor and stored in a temperature of $-4^{\circ} \mathrm{C}$ until use $[41,45]$.

2.2. Determination of Total Polyphenol, Flavonoid, Flavonol, and Anthocyanin Contents. The content of total polyphenols has been quantified by the method of Folin-Ciocalteu according to the protocol described by María et al. [46]. Flavonoids and flavonols have been determined with the colorimetric methods using aluminum chloride, according to the protocols described by Iqbal et al. [47] and Awah et al. [48]. The total anthocyanins have been dosed by the $\mathrm{pH}$ variation method described by Hosseinian et al. [49] and Bhat and Riar [50].

2.3. UPLC-PDA-ESI-MS Analysis. The chemical compounds of E.PG and I.PG have been identified by UPLC in reverse phase using a Waters ACQUITY SDS UPLC system with a Column type: ACQUITY UPLC ${ }^{\circledR}$ BEH C18 $1.7 \mu \mathrm{m}$, as followed in the method of Kachkoul et al. [45]. In this respect, the separation is carried out in gradient mode using acetonitrile $\left(\mathrm{CH}_{3} \mathrm{CN}\right)$ and formic acid $(100: 0.1 \mathrm{v}: \mathrm{v})$ according to the following steps: (1) initial mobile phase including $10 \%$ of $\mathrm{CH}_{3} \mathrm{CN}$, (2) linear increase from $10 \%$ to $25 \%$ of $\mathrm{CH}_{3} \mathrm{CN}$ (0-18 min), (3) $25 \%$ of $\mathrm{CH}_{3} \mathrm{CN}$ (18-21 min), (4) from $25 \%$ to $50 \%$ of $\mathrm{CH}_{3} \mathrm{CN}(21-28 \mathrm{~min}$ ), (5) from $50 \%$ to $100 \%$ of $\mathrm{CH}_{3} \mathrm{CN}$ (28- $29 \mathrm{~min}$ ), and (6) $100 \%$ of $\mathrm{CH}_{3} \mathrm{CN}$ (29-30 min); then the percentage of $\mathrm{CH}_{3} \mathrm{CN}$ has been reduced to $10 \%$ (30-37 $\mathrm{min})$, which allowed a stabilization time of $7 \mathrm{~min}$ before injection of the next sample. $4 \mu \mathrm{L}$ of the sample was injected and the flow rate has been set to $0.4 \mathrm{ml} \cdot \mathrm{min}^{-1}$. UPLC was connected to a PDA diode array detector (Waters ACQUITY) with a detection wavelength range between 190 and $500 \mathrm{~nm}$ and an ion trap mass spectrometer (SYNAPTG2\#UCA014) equipped with an electrospray interface (ESI). Further, the scan range has been set to $\mathrm{m} / z$ which ranges from 50 to 1500 with a scan time of $0.3 \mathrm{~s}$. Hence, the conditions of the ESI were as follows: there has been negative mode and temperature of the source and the desolvation gas was $120^{\circ} \mathrm{C}$ and $450^{\circ} \mathrm{C}$. The flow rate of the cone, desolvation gas (Helium), and the collision $(\mathrm{He})$ is $800 \mathrm{~L} / \mathrm{h}, 20 \mathrm{~L} / \mathrm{h}$, and $0.01 \mathrm{~mL} / \mathrm{min}$, respectively. 


\subsection{Antioxidant Activity}

2.4.1. DPPH (2,2-diphenyl-1-picrylhydrazyl) Method. The antiradical power of the extracts E.PG and I.PG has been tested by the method of DPPH (1,1-diphenyl-2-picrylhydrazyl) as indicated in the protocol described by Wang et al. [51] with small modifications. In fact, a solution of DPPH has been prepared by the solubilization of $4 \mathrm{mg}$ of this latter in $100 \mathrm{~mL}$ of methanol. $750 \mu \mathrm{L}$ of extracts with different concentrations ranging from 0.1 to $2 \mathrm{mg} / \mathrm{mL}$ and ascorbic acid (vitamin C (Vit.C)) with (0.01 to $2 \mathrm{mg} / \mathrm{mL}$ ) are introduced into test tubes. Then $1.5 \mathrm{~mL}$ of the DPPH solution was added. After incubation for $30 \mathrm{~min}$ in the dark and at room temperature, the absorbance $(A)$ has been measured at $\lambda=517 \mathrm{~nm}$. The inhibition percentages have been calculated by the following relationship [45]:

$$
\% \text { antioxidant activity }=\frac{A \text { control-A simple }}{A \text { control }} * 100 \text {. }
$$

\subsubsection{Ferric Reducing Antioxidant Power (FRAP) Method.} The reducing power of the plant extracts has been determined according to the method of Oyaizu [52], which consists in mixing $2.5 \mathrm{~mL}$ of E.PG and I.PG extracts at different concentrations ranging from 0.1 to $2 \mathrm{mg} / \mathrm{mL}$ solubilized in distilled water with $2.5 \mathrm{~mL}$ of phosphate buffer $(0.2 \mathrm{~mol} / \mathrm{L}, \mathrm{pH} 6.6)$ and $2.5 \mathrm{~mL}$ of potassium ferricyanide [ $\mathrm{K} 3 \mathrm{Fe}(\mathrm{CN}) 6](1 \%)$. To add, the mixture has been incubated at $50^{\circ} \mathrm{C}$ for $20 \mathrm{~min}$. A volume of $2.5 \mathrm{~mL}$ of trichloroacetic acid (10\%) has been added to the mixture and then centrifuged at $3000 \mathrm{rpm}$ for $10 \mathrm{~min}$. An aliquot of $2.5 \mathrm{~mL}$ of the upper layer of the solution was mixed with $2.5 \mathrm{~mL}$ of distilled water and $0.5 \mathrm{~mL}$ of $\mathrm{FeCl}_{3}(0.1 \%)$. Absorbance has been measured at $\lambda=700 \mathrm{~nm}$. Ascorbic acid was used as a control $[45,51,53]$.

\subsection{Inhibition of the Calcium Oxalate's Crystallization.} The anticrystallization effect of the plant extracts has been studied according to the protocol described by Hess et al. [54] and repeated by Kachkoul et al. [41, 55]. The stock solutions of $\mathrm{CaCl}_{2}: 2 \mathrm{H}_{2} \mathrm{O}[15 \mathrm{mM}]$ and $\mathrm{Na}_{2} \mathrm{C}_{2} \mathrm{O}_{4}[1.5 \mathrm{mM}]$ containing $\mathrm{NaCl}$ [200 $\mathrm{mM}$ ] have been prepared, to which $10 \mathrm{mM}$ sodium acetate was added to adjust the $\mathrm{pH}$ value to 5.7. Thereafter, the solutions have been filtered through $0.22 \mu \mathrm{m}$ pore diameter filters and then warmed to $37^{\circ} \mathrm{C}$ before being used. For crystallization experiments without inhibitor, $1 \mathrm{~mL}$ of the $\mathrm{CaCl}_{2}: 2 \mathrm{H}_{2} \mathrm{O}$ solution and $1 \mathrm{~mL}$ of the distilled water have been transferred to a quartz cuvette optical path $10 \mathrm{~mm}$; then an identical volume of the $\mathrm{Na}_{2} \mathrm{C}_{2} \mathrm{O}_{4}$ solution has been added to trigger the crystals' formation. Then, the temporal measurements of the optical density "OD" have been recorded every 15 seconds for a period of one hour, using a UV-Visible spectrophotometer at the wavelength $\lambda$ equal to $620 \mathrm{~nm}$, which corresponds to the crystal detection. Similarly, the tests with inhibitors have been performed with several concentrations of $0.5,1$, and $2 \mathrm{~g} / \mathrm{L}$ of I.PG and E.PG extracts and in the same way as the tests without inhibitors, by replacing the distilled water with the extracts. Besides, the slopes of the nucleation phase "SN" and aggregation "SA" have been calculated using linear regression analysis, and the percentages of inhibitions have been calculated by the relation of Hess et al. $[54,56]$

$$
\begin{gathered}
\% \text { nucleation inhibition }=1-\frac{\mathrm{SN} i}{\mathrm{SN} s} * 100, \\
\% \text { aggregation inhibition }=1-\frac{\mathrm{SA} i}{\mathrm{SAs}} * 100,
\end{gathered}
$$

where " $i$ " and " $s$ " represent tests with and without inhibitors, respectively. The correlation coefficient $(R)$ and the coefficient of variation $(\mathrm{CV})$ are calculated to verify the validity of our results.

2.6. Characterization of Crystals. The characterization of the crystals has been performed using an optical microscope, and the determination of the chemical composition has been made by Fourier Transform Infrared Spectroscopy (FT-IR) between 4000 and $400 \mathrm{~cm}^{-1}$ with a resolution of $4 \mathrm{~cm}^{-1}$, on crystals synthesized in the absence and in the presence of inhibitors.

2.7. Statistical Analysis. The results were expressed as mean \pm SD of the three repetitions; the statistical analyses have been carried out by ANOVA One-Way method followed by Tukey's multiple comparison test and correlation of Pearson's using graphPad Prism7; $p<0.05$ is considered as significant.

\section{Results and Discussion}

3.1. Content of Total Polyphenols, Flavonoids, Flavonols, and Anthocyanins. The contents of Total Polyphenol, Flavonoids, Flavonols, and Anthocyanins of the two extracts are illustrated in Figure 1.

As shown in Figure 1, there is no significant variation between the two extracts of the plant for the different chemical families assayed excepted flavonols $(p<0.05)$; the results of the quantification reveal the richness of the pomegranate fruit peel by the total polyphenols, with contents of $109.44 \pm 1.37$ and $111.92 \pm 1.42 \mathrm{mg} \mathrm{GAE} / \mathrm{g}$ for E.PG and I.PG, respectively. With regard to flavonoids and flavonols, which are by definition subclasses of polyphenols, the values obtained are in the order of $36.05 \pm 2.95$ and $37.64 \pm 0.91 \mathrm{mg} E Q / \mathrm{g}$ for the first class and in the order of $7.17 \pm 0.49$ and $9.08 \pm 0.33 \mathrm{mg} \mathrm{EQ} / \mathrm{g}$ for the second class, respectively, for E.PG and I.PG. However, anthocyanins are present in low levels with values of the order of $0.47 \pm 0.096$ and $0.67 \pm 0.16 \mathrm{mgCy}-3 \mathrm{glcE} / \mathrm{g}$ for E.PG and I.PG, respectively. The comparison of these outcomes found in this study with the literature shows that the contents of these extracts far exceed those found by Romeo et al. [57], who reported concentrations of $66.97 \pm 0.67 \mathrm{~g} \mathrm{GAE} / \mathrm{kg}$ for polyphenol and $21.64 \pm 0.03 \mathrm{mg} \mathrm{mgCy}-3 \mathrm{glcE} / \mathrm{kg}$ for anthocyanins. On the other hand, Derakhshan et al. [58] found higher values in three Iranian varieties (Natanz, Shahreza, and Doorak) for 


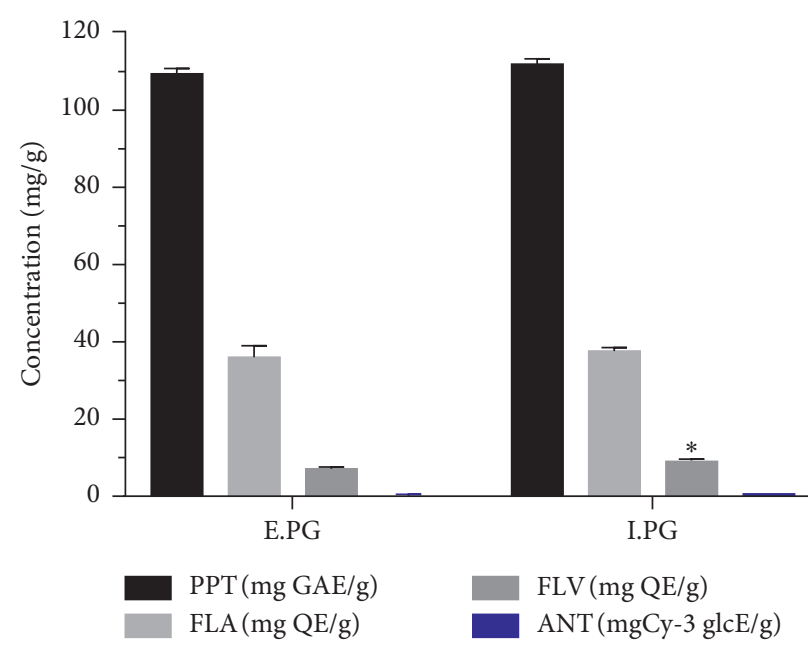

FIgURE 1: Content of total polyphenols, flavonoids, flavonols, and anthocyanins in the extracts of E.PG and I.PG. Values are expressed as mean \pm SD $(n=3) .{ }^{*} p<0.05$ vs. E.PG. E.PG: hydroalcoholic extract of Punica granatum L.; I.PG: infusion of Punica granatum L.; PPT: total polyphenols; FLA: flavonoids; FLV: flavonols; ANT: anthocyanins.

total polyphenols and flavonols, but the flavonoid values remain comparable with this work.

3.2. UPLC-PDA-ESI-MS Analysis. The determination of the likely chemical composition in the E.PG and I.PG extracts of the pomegranate fruit peel was based on comparing the absorbance and the MS spectrum obtained by UPLC-PDAESI-MS with the literature data. The identification results and the chromatographic profile for these two extracts are shown in Figure 2 and in Tables 1 and 2.

The chemical composition of the E.PG extract (Table 1) is dominated by phenolic acid derivatives mainly the Ellagitannins. UPLC chromatogram (Figure 2(a)) of this extract illustrates the presence of 14 peaks. The interpretation of their MS spectra reveals the presence of the following compounds: peaks $\mathbf{1}$ and $\mathbf{2}$ are characterized by the presence of the pseudomolecular ion $[\mathrm{MH}]^{-}$at $\mathrm{m} / \mathrm{z}$ 1083; main fragments have been observed at $m / z 781$ and 301 , indicating the loss of ellagic acid and corresponding to the punicalagin compound [65]. Peaks 3 and 4 with an [M$\mathrm{H}]^{-}$ion at $\mathrm{m} / z 1415$ represent the molecule of Di(HHDPgalloyl-glucose)-pentose [27] or pedunculagin I derivative [60]; this compound produces the fragments at $\mathrm{m} / z 1083$ which corresponds to punicalagin, at $\mathrm{m} / z 633$ and 301, which are characteristics of galloyl-HHDP-hexoside and ellagic acid, respectively (Figure 3) [25, 64, 66].

Peak 5 is tentative identified as Granatin A (ellagic acid derivative) or lagerstannin A (bis-HHDP-gluconic acid) [62], with the pseudomolecular ion $[\mathrm{M}-\mathrm{H}]^{-}$at $\mathrm{m} / z 799$ and the presence of fragment at $m / z 301$ which illustrates the ellagic acid molecule. Peak 7 revealed a molecular ion [M$\mathrm{H}]^{-}$at $m / z 785$ typical of the pedunculagin II molecule (Digalloyl-HHDP-hexoside). Peaks $\mathbf{8}$ and $\mathbf{9}$ are identified as Granatin B (galloyl-HHDP-DHHDP-hexoside) or pedunculagin I derivative; these two peaks are characterized by the presence of a pseudomolecular ion $[\mathrm{M}-\mathrm{H}]^{-}$at $\mathrm{m} / z 951$ $[22,60-62]$, and the fragments have been detected at $\mathrm{m} / z 933$ that represents the loss of a molecule of water ([M-H$\left.\mathrm{H}_{2} \mathrm{O}\right]^{-}$) [63], at $m / z 783$, which can illustrate the loss of the gallic acid molecule ([M-H- acide gallique $]^{-}$) or the pedunculagin I molecule, and at $\mathrm{m} / z$ 301, which typically expresses the fragment of ellagic acid. The peak $\mathbf{1 1}$ displays a pseudomolecular ion $[\mathrm{M}-\mathrm{H}]^{-}$at $m / z 965$ and a fragment at $\mathrm{m} / z 301$ can illustrate the Castalagin derivative $[22,62,64]$. The peak 14 was identified as Vanillic acid-hexoside derivative and exhibits a molecular ion $[\mathrm{MH}]^{-}$at $\mathrm{m} / z 659$ and a fragment at $m / z$ 329; this latter illustrates the molecule of vanillic-hexoside acid. Regarding the infusion, the UPLC chromatogram (Figure 2(b)) shows the presence of 12 peaks; their characterization (Table 2) reveals a similarity with the hydroalcoholic extract, with the absence of the vanillic acidhexoside derivative molecule and the presence of the molecule punigluconin; this latter has not been detected in the first extract.

3.3. Antioxidant Activity. The antioxidant activity has been verified in vitro by DPPH and FRAP methods. In order to judge the importance of the antiradical effect of the E.PG and I.PG extracts, a positive control has been studied using vitamin C (Vit.C) known for its antioxidant power. In fact, percent inhibition and the median inhibitory concentration $\left(\mathrm{IC}_{50}\right)$ are represented in Figure 4 and Table 3.

According to Figure 4(a), corresponding to the reducing activity of the DPPH radical, the inhibition rate increases rapidly in function of the concentration increase for the three products, ended by stabilization at concentrations of $100 \mu \mathrm{g} / \mathrm{mL}$ for Vit.C and $1000 \mu \mathrm{g} / \mathrm{mL}$ for both extracts. The maximum inhibition percentages that correspond to the concentration of $2 \mathrm{mg} / \mathrm{ml}$ are almost similar for both extracts I.PG and E.PG, with a superiority for the second; the values found are in the order of $90.86 \pm 0.55$ ( $p<0.05$ vs. Vit.C) and $91.93 \pm 0.43 \%(p<0.05$ vs. Vit.C) for I.PG and E.PG, respectively. These percentages are close to the positive control (Vit.C) which has a value of $94.74 \pm 0.20 \%$. In addition, the median inhibitory concentration $\left(\mathrm{IC}_{50}\right)$ also exhibits a similarity between the two extracts with values of $60.87 \pm 0.27 \mu \mathrm{g} / \mathrm{mL}(p<0.05$ vs. Vit.C) and $59.91 \pm 0.83 \mu \mathrm{g} /$ $\mathrm{mL}(p<0.05$ vs. Vit.C) for I.PG and E.PG, respectively, against $10.57 \pm 0.61 \mu \mathrm{g} / \mathrm{mL}$ for Vit.C. These data prove the effectiveness of the plant extracts in the process of free radical removal by transforming them into more stable products at low concentrations. In fact, the mechanism of action involves donating hydrogen to a free radical, thereby reducing it to a nonreactive species. The addition of hydrogen removes the characteristic of odd electrons, which are responsible for radical reactivity [51].

The ferric reducing antioxidant power (FRAP) of the two extracts exhibits a great deal of capacity in reducing the $\mathrm{Fe}^{+} /$ferricyanide complex to a ferrous $\mathrm{Fe} 2^{+}$form by the donation of an electron. As shown in Figure 4(b), the absorbance increases correlatively as a function of the concentration and reaches maximum values in the order of $2.70 \pm 0.19$ and $2.81 \pm 0.14$ at concentration of $2 \mathrm{mg} / \mathrm{ml}$ for 


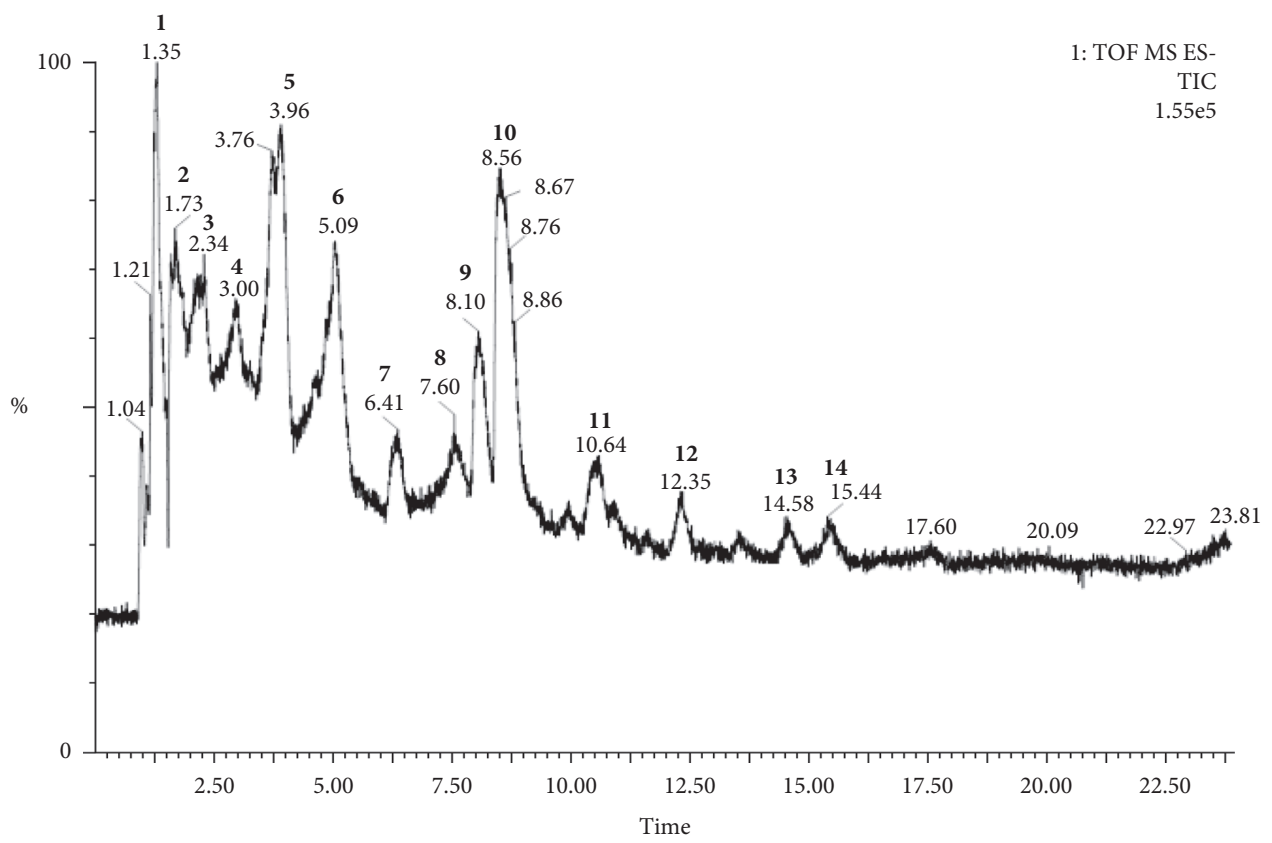

(a)

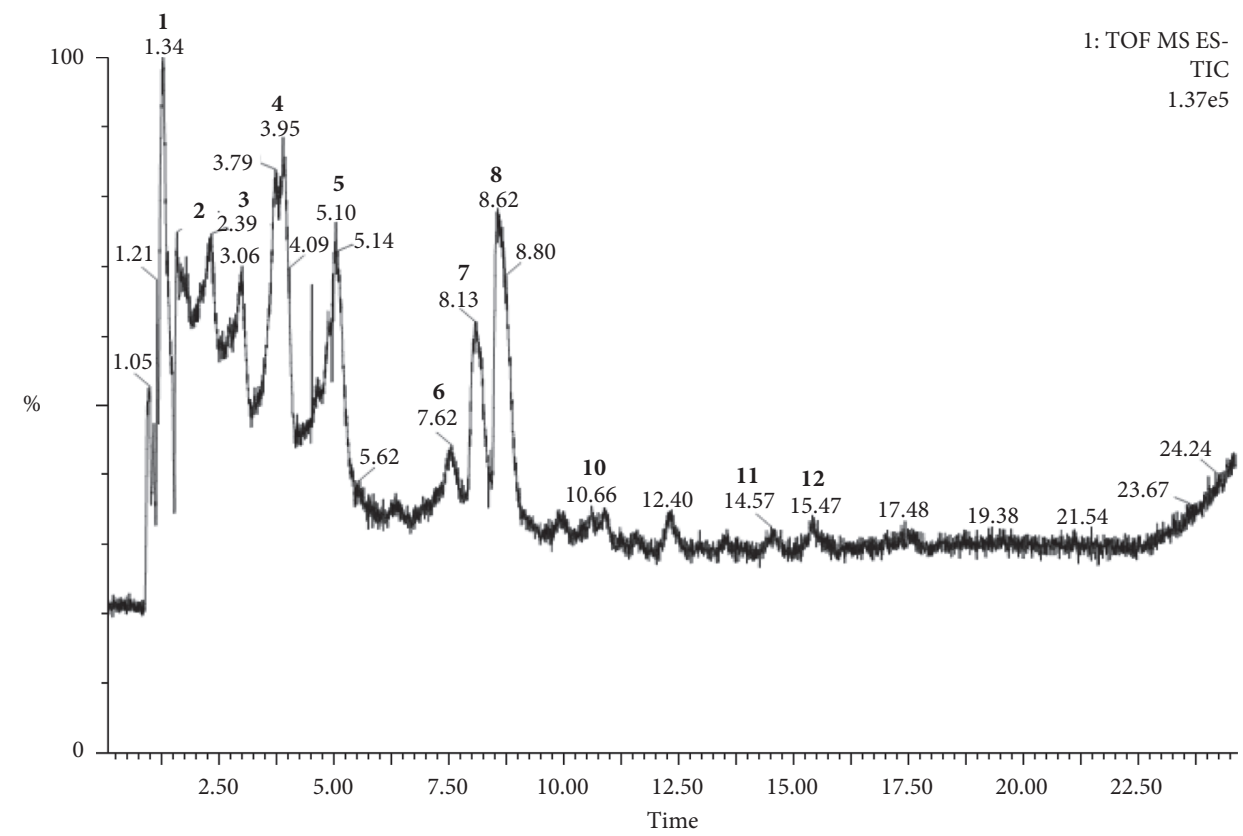

(b)

FIGURE 2: UPLC chromatograms of plant extracts; (a) E.PG and (b) I.PG. E.PG: hydroalcoholic extract of Punica granatum L.; I.PG: infusion of Punica granatum L. The bold numbers marked the peaks, whose names are shown in Tables 1 and 2.

I.PG and E.PG, respectively, whereas, for Vit.C, the absorbance increases rapidly and takes a value of $2.95 \pm 0.078$ at a lower concentration $(0.1 \mathrm{mg} / \mathrm{mL})$. However, the $\mathrm{IC}_{50}$ values which represent the concentration of the studied solutions at 0.5 of absorption prove the efficacy of the E.PG compared to the I.PG, with values of $42.17 \pm 7.46 \mu \mathrm{g} / \mathrm{mL}$ $(p<0.05$ vs. Vit.C) and $79.77 \pm 6.91 \mu \mathrm{g} / \mathrm{mL} \quad(p<0.05$ vs. Vit.C), respectively, while the solution of Vit.C reveals a value of $1.94 \pm 0.14 \mu \mathrm{g} / \mathrm{mL}$. In this respect, the DPPH method outcomes in this work are approximating those reported by
Abid et al. [64] who worked on different extracts of the Tunisian varieties (Acid, Gabsi, Nebli, and Tounsi) and provide reduction values between $71.11 \%$ and $97.82 \%$, as well as the works of Šavikin et al. [67] and Pagliarulo et al. [68]. Moreover, this antiradical efficacy of these extracts is probably due to the presence of ellagic acid derivatives such as punicalagin. The ability of this molecule in free radical scavenging has been demonstrated by Aguilar-Zárate et al. [69] and the values found are more than $90 \%$ at a concentration of $250 \mu \mathrm{g} / \mathrm{ml}$ and an $\mathrm{IC}_{50}$ of $109.53 \mu \mathrm{g} / \mathrm{mL}$. 
TABLE 1: Chemical compounds identified in hydroalcoholic extract of Punica granatum L.

\begin{tabular}{|c|c|c|c|c|c|c|}
\hline Peak & $\begin{array}{c}\mathrm{RT} \\
(\mathrm{min})\end{array}$ & $\begin{array}{c}{[\mathrm{M}-\mathrm{H}]^{-}} \\
(\mathrm{m} / z)\end{array}$ & PDA & Fragment ions $(m / z)$ & Putative identity & Reference \\
\hline 1 & 1.35 & 1083 & $\begin{array}{l}226 / 257 / \\
378\end{array}$ & $1083 / 781 / 481 / 301$ & Punicalagin & {$[26,57,59]$} \\
\hline 2 & 1.73 & 1083 & $\begin{array}{l}216 / 261 / \\
378\end{array}$ & $1083 / 781 / 633 / 483 / 301$ & Punicalagin & {$[26,57,59]$} \\
\hline 3 & 2.34 & 1415 & $\begin{array}{l}220 / 257 / \\
377\end{array}$ & $\begin{array}{c}1415 / 1083 / 783 / 633 / \\
425 / 301\end{array}$ & $\begin{array}{l}\text { Di(HHDP-galloyl-glucose)-pentose Pedunculagin I } \\
\text { derivative }\end{array}$ & {$[22,27,60]$} \\
\hline 4 & 3.00 & 1415 & $\begin{array}{c}219 / 257 / \\
377\end{array}$ & $\begin{array}{c}1415 / 1083 / 783 / 633 / \\
483 / 301\end{array}$ & $\begin{array}{l}\text { Di(HHDP-galloyl-glucose)-pentose Pedunculagin I } \\
\text { derivative }\end{array}$ & {$[22,27,60]$} \\
\hline 5 & 3.96 & 799 & & $799 / 301 / 247$ & Granatin A ellagic acid derivative & {$[22,61,62]$} \\
\hline 6 & 5.09 & 927 & $252 / 361$ & $927 / 813 / 633 / 463 / 300$ & Unknown & \\
\hline 7 & 6.41 & 785 & & $785 / 601 / 247$ & Pedunculagin II (digalloyl-HHDP-hexoside) & {$[22,62,63]$} \\
\hline 8 & 7.6 & 951 & $220 / 255$ & $\begin{array}{l}951 / 933 / 783 / 433 / 301 / \\
216\end{array}$ & $\begin{array}{l}\text { Granatin B (galloyl-HHDP-DHHDP-hexoside)/ } \\
\text { pedunculagin I derivative }\end{array}$ & {$[22,60-62]$} \\
\hline 9 & 8.10 & 951 & $\begin{array}{c}197 / 252 / \\
361\end{array}$ & $\begin{array}{l}951 / 867 / 783 / 433 / 301 / \\
216\end{array}$ & $\begin{array}{l}\text { Granatin B (galloyl-HHDP-DHHDP-hexoside)/ } \\
\text { pedunculagin I derivative }\end{array}$ & {$[22,57,61,62]$} \\
\hline 10 & 8.56 & 301 & $252 / 367$ & 301 & Ellagic acid & {$[22,26,62]$} \\
\hline 11 & 10.64 & 965 & & $\begin{array}{l}965 / 951 / 319 / 301 / 273 / \\
217\end{array}$ & Castalagin der & {$[22,62,64]$} \\
\hline 12 & 12.35 & 917 & & $917 / 703 / 585 / 425 / 216$ & Unknown & \\
\hline 13 & 14.58 & 907 & & $907 / 633 / 447 / 292 / 216$ & Unknown & \\
\hline 14 & 15.44 & 659 & & $659 / 390 / 329 / 216$ & Vanillic acid-hex der & [22] \\
\hline
\end{tabular}

TABle 2: Chemical compounds identified in infusion of Punica granatum L.

\begin{tabular}{|c|c|c|c|c|c|c|}
\hline Peak & $\begin{array}{c}\mathrm{RT} \\
(\mathrm{min})\end{array}$ & $\begin{array}{c}{[\mathrm{M}-\mathrm{H}]^{-}} \\
(\mathrm{m} / \mathrm{z})\end{array}$ & PDA & Fragment ions $(m / z)$ & Putative identity & Reference \\
\hline 1 & 1.34 & 1083 & $228 / 257$ & $1083 / 781 / 633 / 481 / 301$ & Punicalagin & {$[26,57,59]$} \\
\hline 2 & 2.39 & 1265 & $377 / 257$ & $\begin{array}{c}1265 / 1083 / 783 / 633 / 541 / 425 / 301 / \\
275\end{array}$ & Pedunculagin I derivative & {$[22]$} \\
\hline 3 & 3.06 & 1415 & $\begin{array}{c}220 / 257 / \\
378\end{array}$ & $1415 / 1083 / 753 / 633 / 483 / 301 / 275$ & Di(HHDP-galloyl-glucose)-pentose & {$[27]$} \\
\hline 4 & 3.95 & 801 & & $801 / 479 / 301 / 247$ & Digalloyl-HHDP-glucose (punigluconin) & {$[22,62,63]$} \\
\hline 5 & 5.10 & 927 & $252 / 361$ & $927 / 813 / 633 / 463 / 301$ & Unknown & \\
\hline 6 & 7.62 & 951 & & $951 / 783 / 433 / 301 / 217$ & $\begin{array}{c}\text { Granatin B (galloyl-HHDP-DHHDP- } \\
\text { hexoside) }\end{array}$ & {$[22,61,62]$} \\
\hline 7 & 8.13 & 951 & $\begin{array}{c}196 / 252 / \\
361\end{array}$ & $951 / 447 / 433 / 301 / 217$ & $\begin{array}{c}\text { Granatin B (galloyl-HHDP-DHHDP- } \\
\text { hexoside) }\end{array}$ & {$[22,61,62]$} \\
\hline 8 & 8.62 & 301 & $252 / 367$ & 301 & Ellagic acid & {$[22,26,62]$} \\
\hline 9 & 10.94 & 965 & & $965 / 477 / 301 / 292 / 217$ & Castalagin der & {$[22,62]$} \\
\hline 10 & 12.40 & 585 & & $585 / 451 / 292 / 217$ & Unknown & \\
\hline 11 & 14.57 & 907 & & $907 / 391 / 329 / 217$ & Unknown & \\
\hline 12 & 15.47 & 659 & & $659 / 391 / 329 / 217$ & Unknown & \\
\hline
\end{tabular}

3.4. Inhibition of the Calcium Oxalate's Crystallization. The preventive effect of the E.PG and I.PG extracts of the plant Punica granatum L. against the calcium oxalate's crystallization has been studied in vitro by the turbidimetric model in absence (SI) and presence of inhibitors. This model allows following the steps of crystallization, in particular, the nucleation and aggregation stages. In fact, the inhibition percentages of the last two have been calculated from the comparison of the slopes in the presence of the extracts with that without inhibitor and the outcomes are displayed in Table 4.

The analysis of the data in Table 4 shows a high efficiency of the two plant extracts in a dose-dependent manner in inhibiting the nucleation of calcium oxalate crystals. In fact, the inhibition percentages are in order of $93.38 \pm 0.09,94.97 \pm 0.21$, and $98.11 \pm 0.17 \%(P<0.05$ vs. Cit.K $)(R>0.95, \mathrm{CV}<10 \%)$ for E.PG at concentrations of $0.5,1$, and $2 \mathrm{~g} / \mathrm{L}$, respectively, and in the order of $93.01 \pm 1.22 \%(P<0.05$ vs. Cit.K), $97.59 \pm 0.30$, and $98.22 \pm 0.71 \%(R>0.95, \mathrm{CV}<10 \%)$ for I.PG at concentrations of $0.5,1$, and $2 \mathrm{~g} / \mathrm{L}$, respectively, whereas, for potassium citrate (Cit.K) taken as a positive control, the values found are in the order of $96.52 \pm 0.01,97.01 \pm 0.06$, and $97.37 \pm 0.16 \%(R>0.95$, $\mathrm{CV}<10 \%)$ at concentrations of $0.5,1$, and $2 \mathrm{~g} / \mathrm{L}$, respectively [55]. Nevertheless, the analysis of the images taken during this phase (Figure 5(a)) displays that the number and the size become less important in presence of the extracts of E.PG, I.PG, and Cit.K solution. This reflects the results of the turbidity 


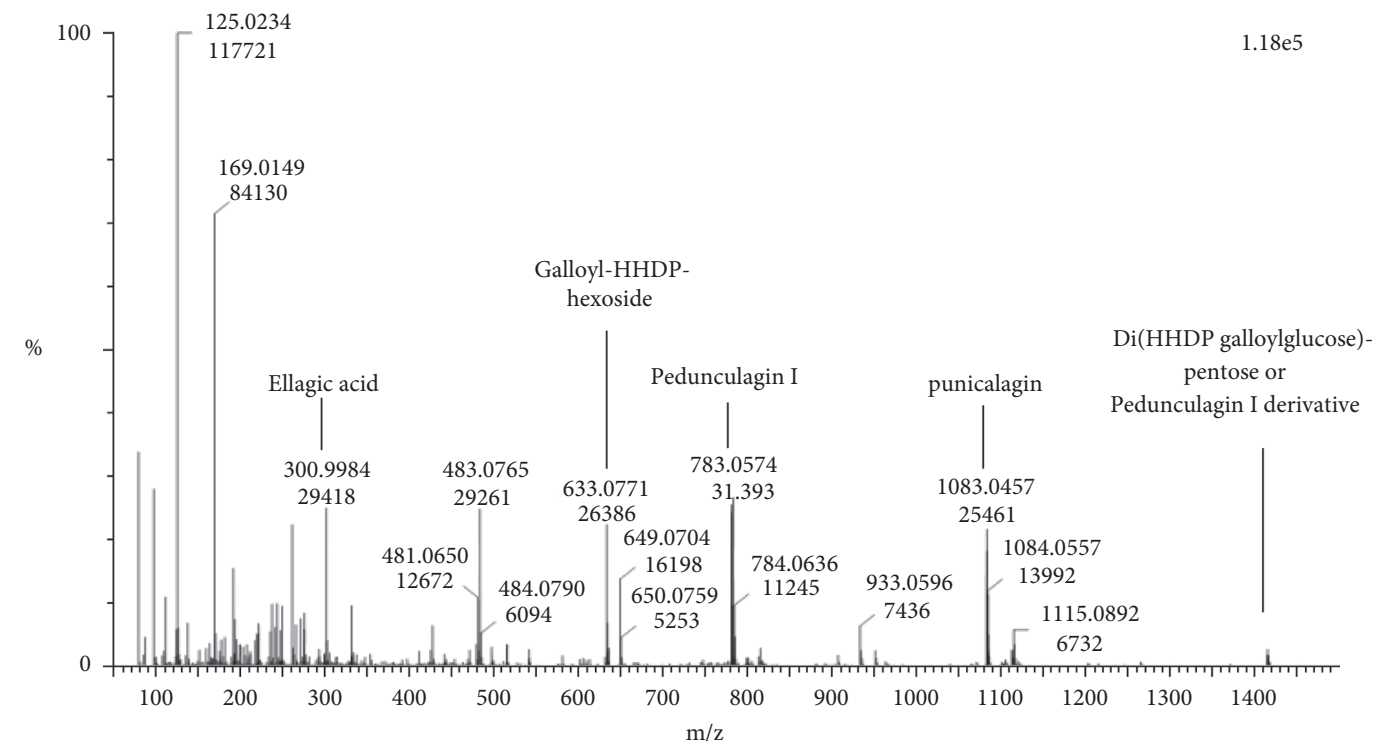

FIGURE 3: MS spectrum of the molecule Di(HHDP-galloyl-glucose)-pentose or pedunculagin I derivative present in both plant extracts.

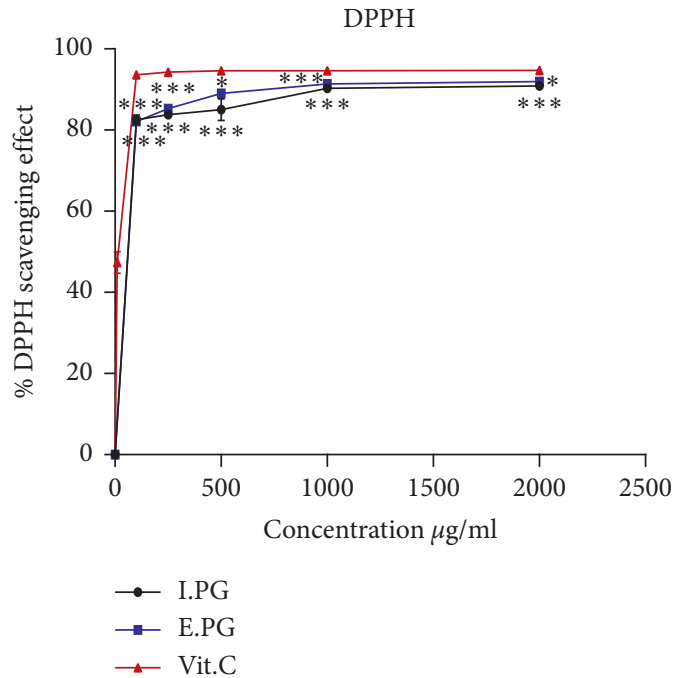

(a)

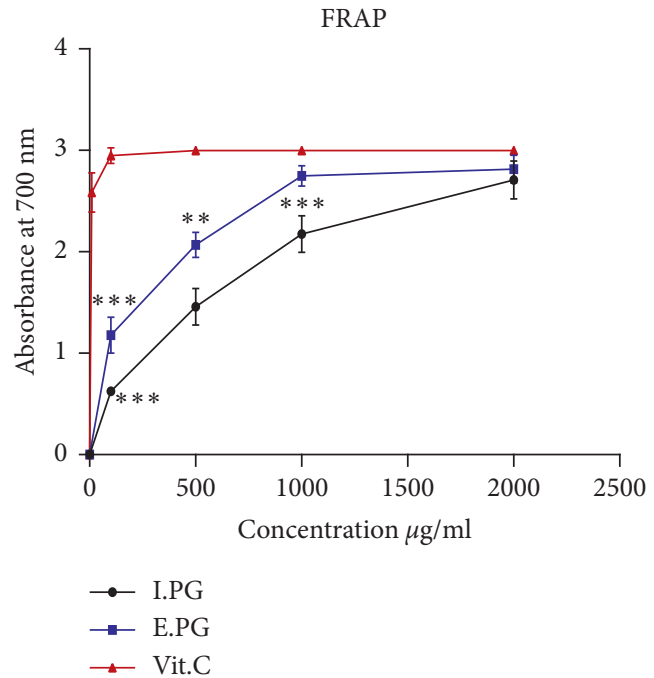

(b)

Figure 4: Antioxidant effect of I.PG I.PG and Vit.C. (a) Percent inhibition of free DPPH. (b) Ferric reducing power. Values are expressed as mean \pm SD $(n=3)$. E.PG: hydroalcoholic extract of Punica granatum L.; I.PG: infusion of Punica granatum L.; Vit.C: vitamin C. ${ }^{*} p<0.05$; ${ }^{* *} p<0.01 ;{ }^{* * *} p<0.005$ vs. Vit.C group.

TABle 3: IC $_{50}$ values of E.PG, I.PG, and Vit.C obtained with the DPPH and FRAP method.

\begin{tabular}{lcc}
\hline \multirow{2}{*}{ Extract } & \multicolumn{2}{c}{ IC $_{50}$ value $(\mu \mathrm{g} / \mathrm{ml})$} \\
& DPPH & FRAP \\
\hline E.PG & $60.87 \pm 0.27^{* * *}$ & $42.17 \pm 7.46^{*}$ \\
I.PG & $59.91 \pm 0.83^{* * *}$ & $79.77 \pm 6.91^{* *}$ \\
V.C & $10.57 \pm 0.61$ & $1.94 \pm 0.14$ \\
\hline
\end{tabular}

Values are expressed as mean $\pm \mathrm{SD}(n=3)$. E.PG: hydroalcoholic extract of Punica granatum L.; I.PG: infusion of Punica granatum L.; Vit.C: vitamin C. ${ }^{*} p<0.05 ;{ }^{* *} p<0.01 ;{ }^{* * *} p<0.005$ vs. Vit.C group. model and confirms the effect of the plant extracts in nucleation inhibition, which appears to be more effective than the Cit.K solution.

Regarding the aggregation phase (Table 4), a similarity of inhibition rate has been observed in both extracts of E.PG and I.PG. Indeed, the inhibition rate of the latter is in the order of $72.28 \pm 1.30, \quad 84.66 \pm 0.82$, and $88.78 \pm 2.48 \%$ $(p<0.05$ vs. Cit.K) $(R>0.95, \mathrm{CV}<10 \%)$ for concentrations of $0.5,1$, and $2 \mathrm{~g} / \mathrm{L}$, respectively; also, the extract E.PG reveals values of $81.50 \pm 0.99,83.08 \pm 1.54$, and $88.98 \pm 0.98 \%$ $(p<0.05$ vs. Cit.K) $(R>0.95, \mathrm{CV}<10 \%)$, respectively, for 

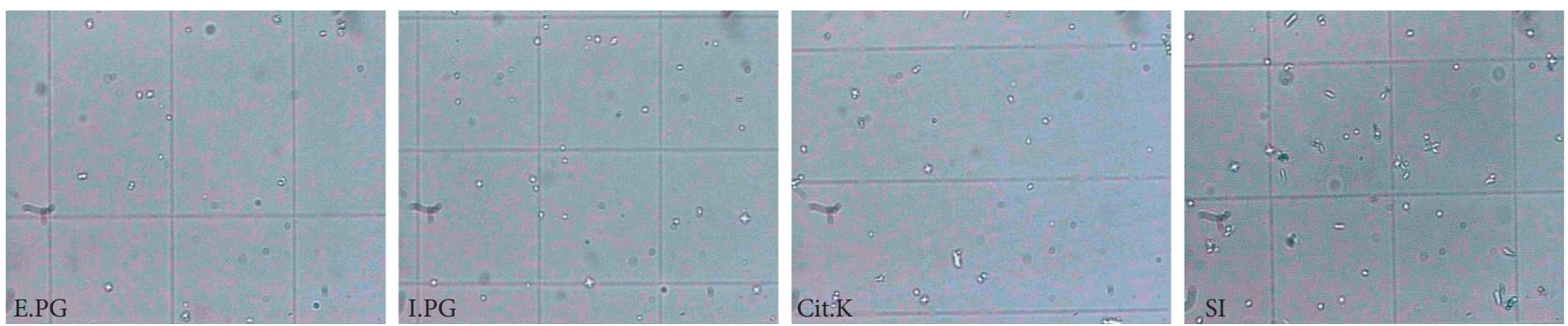

(a)
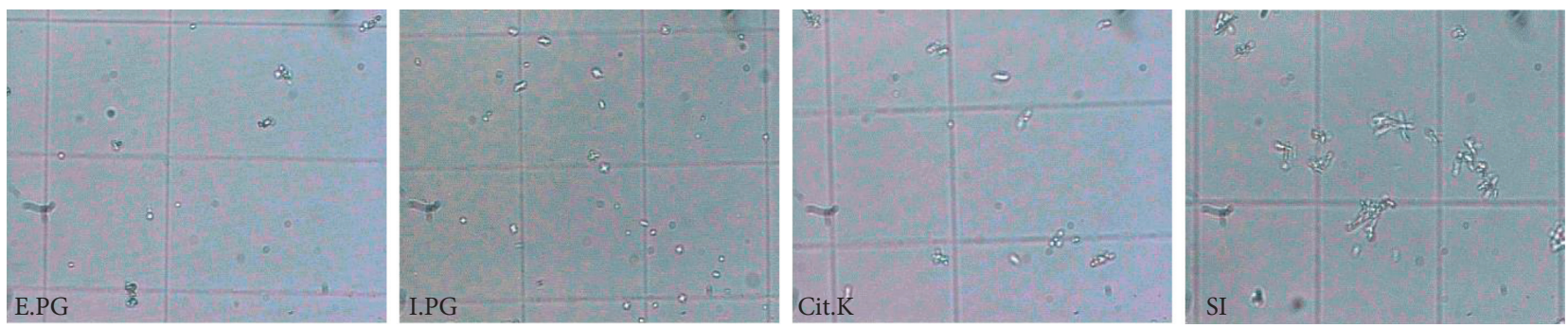

(b)

FIgURE 5: Crystals of calcium oxalate in the stages of nucleation (a) and aggregation (b). E.PG: hydroalcoholic extract of Punica granatum L.; I.PG: infusion of Punica granatum L.; Cit.K: potassium citrate.

TABle 4: Percent inhibition of nucleation and aggregation in the presence of plant extracts and Cit.K solution.

\begin{tabular}{|c|c|c|c|c|c|c|}
\hline \multirow{2}{*}{ Concentration $\mathrm{g} / \mathrm{l}$} & \multicolumn{3}{|c|}{ Nucleation \% } & \multicolumn{3}{|c|}{ Aggregation \% } \\
\hline & E.PG & I.PG & CIT.K $₫$ & E.PG & I.PG & Cit.K $₫$ \\
\hline 0.5 & $93.38 \pm 0.09^{* a \#}$ & $93.01 \pm 1.22^{* \mathrm{a} \#}$ & $96.52 \pm 0.01^{\mathrm{a} \#}$ & $81.50 \pm 0.99^{* * a \#}$ & $72.28 \pm 1.30^{* a \#}$ & $68.25 \pm 2.4^{\mathrm{a} \#}$ \\
\hline 1 & $94.97 \pm 0.21^{* \text { *a\# }}$ & $97.59 \pm 0.30^{\mathrm{a} \#}$ & $97.01 \pm 0.06^{\mathrm{a} \#}$ & $83.08 \pm 1.54^{* \text { *a\# }}$ & $84.66 \pm 0.82^{* * a \#}$ & $69.70 \pm 2.85^{\mathrm{a} \#}$ \\
\hline 2 & $98.11 \pm 0.17^{\text {*a\# }}$ & $98.22 \pm 0.71^{\mathrm{a} \#}$ & $97.37 \pm 0.16^{\mathrm{a} \#}$ & $88.98 \pm 0.98^{* a \#}$ & $88.78 \pm 2.48^{* a \#}$ & $77.12 \pm 2.16^{\mathrm{a} \#}$ \\
\hline
\end{tabular}

Values are expressed as mean $\pm \mathrm{SD}(n=3)$. E.PG: hydroalcoholic extract of Punica granatum L.; I.PG: infusion of Punica granatum L.; Cit.K: potassium citrate. §: Kachkoul et al. [55]. ${ }^{*} p<0.05{ }^{* *} p<0.01$ vs. Vit.C. ${ }^{a} R>0.95 .{ }^{\#} \mathrm{CV}<10 \%$.

concentrations of $0.5,1$, and $2 \mathrm{~g} / \mathrm{L}$, while the Cit.K solution shows a less important effect than the two extracts, with inhibition rate of $68.25 \pm 2.4,69.70 \pm 2.85$, and $77.12 \pm 2.16 \%$ $(R>0.95, \mathrm{CV}<10 \%)$ for the same concentrations [55]. In addition, the image analysis relating to this phase (Figure 5(b)) exhibits the presence of larger and more numerous aggregates in the absence of inhibitor, while the size and the number of crystals become less important in the case of the treatment, especiallyE.PG and the I.PG. Moreover, the results of this study are more important than our subsequent results on crude methanolic extracts of the same plant and those of Ammi visnaga [55], as well as the hydroethanolic extract and the infusion of $A$. unedo leaves [41]. Similarly, they far exceed those of Sharma et al. [70] who worked on the aqueous extract of the Chenopodium album leaves and Cystone.

These outcomes can be explained by the presence of polar compounds in the plant extracts such as polyphenols, flavonoid, and tannins (derived from gallic acids) (Figure 1 and Tables 1 and 2). These compounds probably act through their ability of forming soluble chemical species that will reduce the risk of crystallization or by adsorption on the surface of crystals due to their numerous anionic charges and consequently an inhibition of crystal growth and aggregation. In addition, their fixations on the crystallites lead to an alteration of electrical attraction's phenomena between the atoms situated on the surface of the crystal and the ions present in the solution [12]. This mechanism was partially demonstrated by Noorafshan et al. [71] who reported that Diosmin which is a flavonoid prevents $\mathrm{CaC}_{2} \mathrm{O}_{4}$ deposition on crystals.

\subsection{Crystal's Characterization by Fourier Transform Infrared} Spectroscopy (FT-IR). The determination of the crystals synthesized chemical constitution in the absence and presence of the different concentrations plant extracts, as well as their transformations in terms of their types, has been carried out by the Fourier transform infrared spectroscopy (FT-IR). The spectra obtained are illustrated in Figure 6.

The analysis of the spectra displayed in Figure 6 exhibits that, in the absence of inhibitor (SI), the presence of two bands at 3509 and $3429 \mathrm{~cm}^{-1}$ critical to the $\mathrm{OH}$ stretching of the water, an out-of-plane $\mathrm{C}-\mathrm{O}$ deformation band, and another O-C-O plane bending have been observed at 782 and $515 \mathrm{~cm}^{-1}$, respectively $[72,73]$. While absorption bands have been observed at $1671 / 1619 \mathrm{~cm}^{-1}$ and $1383 / 1325 \mathrm{~cm}^{-1}$, the first are attributed to the stretching band antisymmetric carbonyls (vas $\left(\mathrm{COO}^{-}\right)$) and the second are compatible with the symmetrical stretching band of the metal-carboxylate (vs 


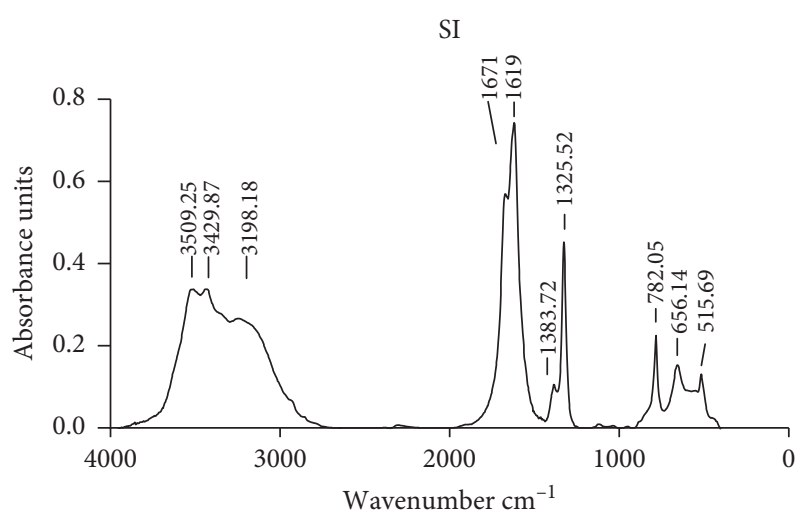

(a)

I.PG $0.5 \mathrm{~g} / \mathrm{l}$

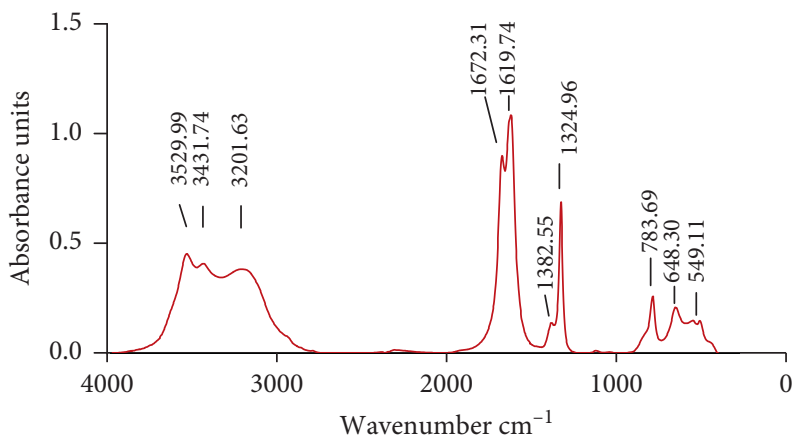

(c)

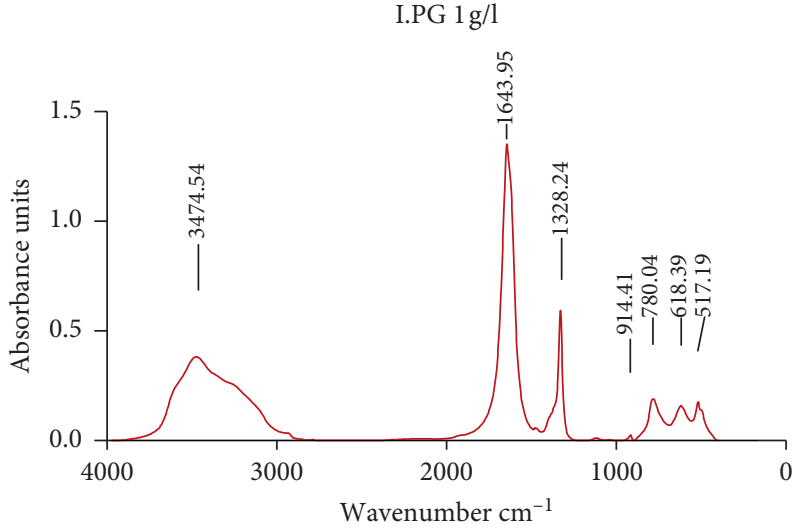

(e)

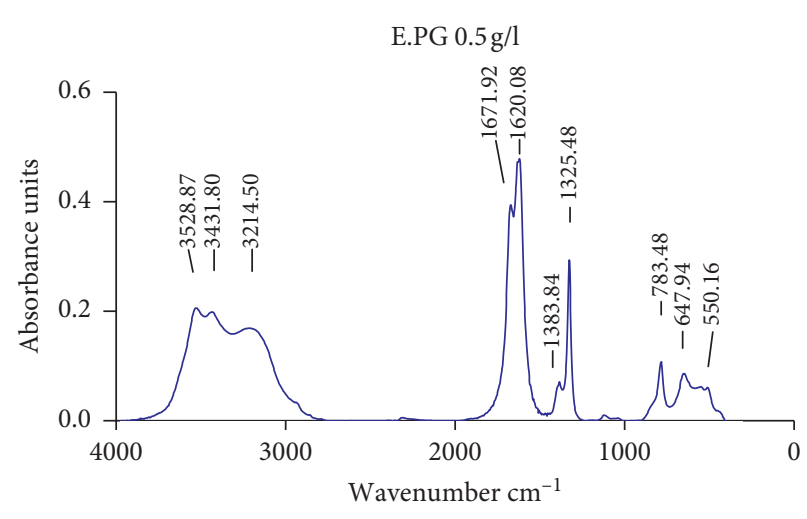

(b)

E.PG1g/1

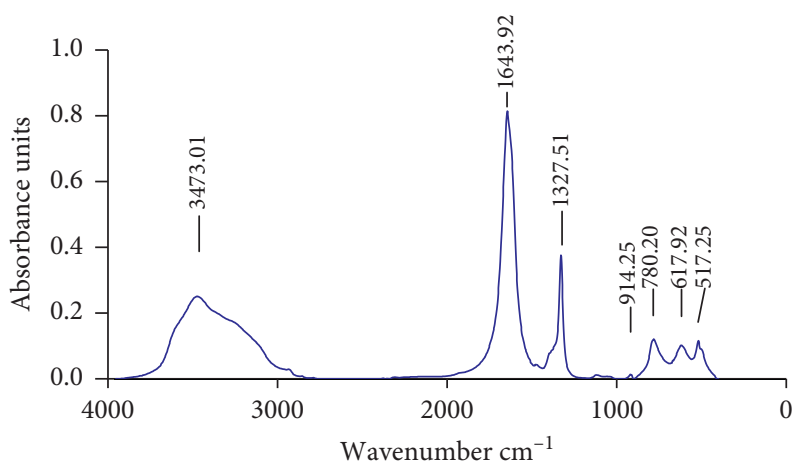

(d)

E.PG $2 \mathrm{~g} / \mathrm{l}$

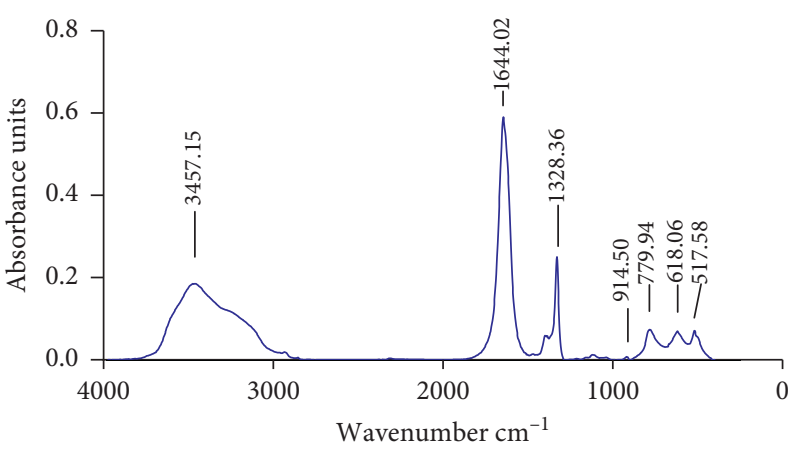

(f)

I.PG $2 \mathrm{~g} / \mathrm{l}$

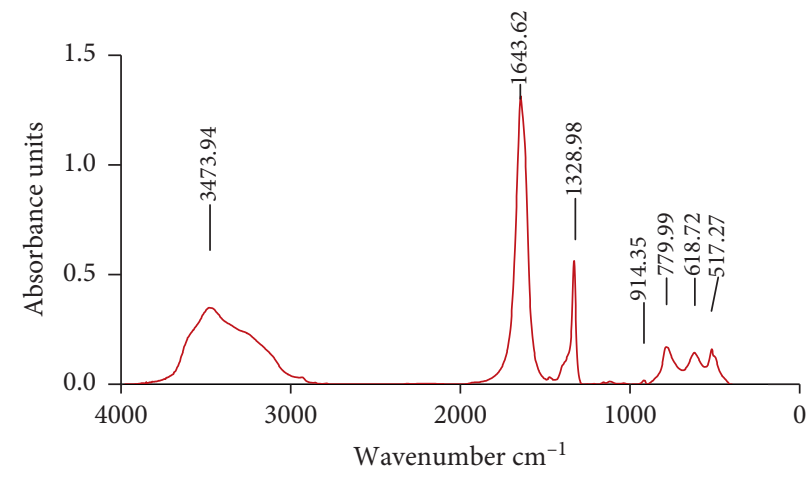

(g)

FIGURE 6: FT-IR spectra of the calcium oxalate crystals in absence (IS) and presence of the different concentrations of E.PG and I.PG. SI: absence of inhibitor; E.PG: hydroalcoholic extract of Punica granatum L.; I.PG: infusion of Punica granatum L. 
TABLE 5: Correlation between phenolic compounds and antioxidant and anticrystallization activity of I.PG extract.

\begin{tabular}{lccccccc}
\hline & DPPH & FRAP & PPT & FLA & FLV & ANT & \% N \\
\hline DPPH & 1 & & & & & & \\
FRAP & 0.694 & 1 & $0.917^{* *}$ & 1 & & & \\
PPT & 0.484 & $0.917^{* *}$ & $1^{* * *}$ & 1 & & & \\
FLA & 0.484 & $0.917^{* *}$ & $1^{* * *}$ & $1^{* * *}$ & 1 & & \\
FLV & 0.484 & $0.917^{* *}$ & $1^{* * *}$ & $1^{* * *}$ & $1^{* * *}$ & 1 & \\
ANT & 0.484 & $0.951^{*}$ & 0.711 & 0.711 & 0.711 & 0.711 & 1 \\
$\%$ N & $1^{* * *}$ & $0.977^{*}$ & 0.787 & 0.787 & 0.787 & 0.787 & $0.994^{* *}$ \\
$\%$ A & $0.993^{* *}$ & & & & \\
\hline
\end{tabular}

I.PG: infusion of Punica granatum L.; PPT: total polyphenols; FLA: flavonoids; FLV: flavonols; ANT: anthocyanins; \% N:\% nucleation inhibition; \%A: \% aggregation inhibition. ${ }^{*}$ Correlation is significant at $p<0.05 .{ }^{* *}$ Correlation is significant at $p<0.01 .{ }^{* * *}$ Correlation is significant at $p<0.005 .{ }^{* * * *}$ Correlation is significant at $p<0.001$.

TABLE 6: Correlation between phenolic compounds and antioxidant and anticrystallization activity of E.PG extract.

\begin{tabular}{|c|c|c|c|c|c|c|c|c|}
\hline & $\mathrm{DPPH}$ & FRAP & PPT & FLA & FLV & ANT & $\% \mathrm{~N}$ & $\% \mathrm{~A}$ \\
\hline DPPH & 1 & & & & & & & \\
\hline FRAP & 0.790 & 1 & & & & & & \\
\hline $\mathrm{PPT}$ & 0.490 & $0.845^{*}$ & 1 & & & & & \\
\hline FLA & 0.490 & $0.845^{*}$ & $1^{* * *}$ & 1 & & & & \\
\hline FLV & 0.490 & $0.845^{*}$ & $1^{* * *}$ & $0.999^{* * *}$ & 1 & & & \\
\hline ANT & 0.490 & $0.845^{*}$ & $1^{* * * *}$ & $1^{* * *}$ & $1^{* * *}$ & 1 & & \\
\hline$\% \mathrm{~N}$ & $0.998^{* *}$ & $0.977^{*}$ & 0.736 & 0.736 & 0.736 & 0.736 & 1 & \\
\hline$\% \mathrm{~A}$ & $1^{* * *}$ & $0.972^{*}$ & 0.713 & 0.713 & 0.713 & 0.713 & $0.999^{* * *}$ & 1 \\
\hline
\end{tabular}

E.PG: hydroalcoholic extract of Punica granatum L.; PPT: total polyphenols; FLA: flavonoids; FLV: flavonols; ANT: anthocyanins; \% N:\% nucleation inhibition; \%A: \% aggregation inhibition. ${ }^{*}$ Correlation is significant at $p<0.05 .{ }^{* *}$ Correlation is significant at $p<0.01 .{ }^{* * *}$ Correlation is significant at $p<0.005 .{ }^{* * * *}$ Correlation is significant at $p<0.001$.

$\left.\left(\mathrm{COO}^{-}\right)\right)$; these bands are corresponding to crystals of $\mathrm{COT}$ [73-76]. Moreover, in the presence of E.PG and I.PG extracts, at a concentration of $0.5 \mathrm{~g} / \mathrm{L}$, multiple bands have been observed between 3200 and $3530 \mathrm{~cm}^{-1}$ critical to the $\mathrm{OH}$ stretching of the water, as well as the presence of a pointed bending band in the plane at $783 \mathrm{~cm}^{-1}$ corresponding to the bands of COM crystals [74]. The existence of bands at $648 \pm 1$ and $550 \pm 1 \mathrm{~cm}^{-1}$ and absorption bands (vas $\left(\mathrm{COO}^{-}\right)$) at $1672 / 1620 \mathrm{~cm}^{-1}$ and $\left(\mathrm{vs}\left(\mathrm{COO}^{-}\right)\right)$at $1383 /$ $1325 \mathrm{~cm}^{-1}$ asserts the formation of COT crystals [74, 75], so that it meant a mixture of $\mathrm{COM}+\mathrm{COT}$ crystals. Besides that, in the presence of E.PG and I.PG at concentrations of 1 and $2 \mathrm{~g} / \mathrm{L}$, a single peak of absorption between 3474 and $3457 \mathrm{~cm}^{-1}$ has been founded, affirming the presence the COD crystals. In [77], a bending band out of the water at $780 \mathrm{~cm}^{-1}$ [78] and also two absorption bands have been observed at $1644 \mathrm{~cm}^{-1}$ for $\left(\right.$ vas $\left.\left(\mathrm{COO}^{-}\right)\right)$and $1328 \mathrm{~cm}^{-1}$ for (vs $\left.\left(\mathrm{COO}^{-}\right)\right)$attesting the formation of $\mathrm{COD}[74,79]$.

3.6. Correlation between Phenolic Compounds and Antioxidant and Anti-crystallization Activities. The relationship between phenolic compounds and antioxidant and anticrystallization activities has been investigated by Pearson's correlation method, and the results are displayed in Tables 5 and 6.

The analysis of Pearson's correlation of I.PG and E.PG extracts (Tables 5 and 6) reveals a similarity of the correlation behavior in both plant extracts. Indeed, these data show a significant relationship between the DPPH radical reducing activity and the anticrystallization activity of calcium oxalate in the nucleation stage $[(R=1, p<0.005$ for I.PG) $(R=0.998, p<0.01$ for E.PG $)]$ and in the aggregation stage $[(R=.0 .993 ; p<0.01))(R=1, p<0.005$ for E.PG $)]$. A significant correlation between these last two stages and the ferric reducing power (FRAP) has been observed with $[(R=0.951, p<0.05$ for I.PG $)(R=0.977, p<0.05$ for E.PG $)$ for the nucleation and $[(R=0.977, p<0.05$ for I.PG $))$ $(R=0.972, p<0.05$ for E.PG)] for aggregation. Also, there wasa strong correlation between the two stages of calcium oxalate crystallization $[(R=0.994, p<0.001$ for I.PG $)$ $(R=0.999, p<0.005)$ for E.PG]. These outcomes can be explained in the way that the process of preventing the oxalate complexation with calcium and the inhibition of $\mathrm{CaC}_{2} \mathrm{O}_{4}$ deposit formation on crystals on the one hand and the process of the free radicals' removal by active ingredients of the extracts on the other hand act in a dependent manner and probably share the same reaction mechanism. Moreover, a strong correlation between the ferric reducing power and the phenolic compounds has been observed $[(0.917 \leq R \leq 0.977, p<0.05$ for I.PG $))(0.845 \leq R \leq 0.977$, $p<0.05$ for E.PG)]; it suggests that the ability of the extracts in reducing the ferricyanide $\left(\mathrm{Fe}^{+}\right)$complex to form more stable ferrous $\left(\mathrm{Fe}^{+}\right)$was directly proportional to the phenolic compounds concentration [80].

\section{Conclusion}

This work highlights the high efficiency of the two fruit peel extracts of Punica granatum L. plant in the inhibition of the DPPH radical and a great reducing power of the $\mathrm{Fe}^{+} /$ 
ferricyanide complex; this capacity has been demonstrated by low $\mathrm{IC}_{50}$ values which are $59.91 \pm 0.83$ and $42.17 \pm 7.46 \mu \mathrm{g} / \mathrm{mL}$ for the DPPH and FRAP methods, respectively. Moreover, a large calcium oxalate anticrystallization effect has been revealed with inhibition percentages of $98.22 \pm 0.71$ and $88.98 \pm 0.98 \%$ for the nucleation and the aggregation stages, respectively. The analysis by Fourier Transform Infrared Spectroscopy (FT-IR) displays the formation of COD crystals in the presence of extracts at concentrations greater than $1 \mathrm{~g} / \mathrm{L}$; these crystals have a low affinity for renal tubular cells. Yet, in the absence and presence of the extracts at low concentrations, there is formation of COM crystals and mixture of COT + COM. In parallel, a significant correlation between the anticrystallization and antioxidant activities has been revealed. However, these excellent activities of the plant can be attributed to higher levels of phenolic compounds quantified and identified by UPLC-PDA-MS, suggesting that it may have prospective use as preventive and/or therapeutic agents for urolithiasis and oxidative stress-related diseases.

\section{Data Availability}

The data used to support the findings of this study are available from the corresponding author upon request.

\section{Conflicts of Interest}

The authors wish to confirm that there are no known conflicts of interest associated with this publication.

\section{Acknowledgments}

The authors thank Professor Amina BARI (Department of Biology, Faculty of Sciences Dhar El-Mahraz, Sidi Mohammed Ben Abdellah University, Fez, Morocco) for the identification of the plant.

\section{References}

[1] V. Castiglione, F. Jouret, O. Bruyère et al., "Épidémiologie de la lithiase urinaire en belgique sur base d'une classification morpho-constitutionnelle," Néphrologie \& Thérapeutique, vol. 11, no. 1, pp. 42-49, 2015.

[2] M. Daudon, "Épidémiologie actuelle de la lithiase rénale en France," EMC-Urologie, vol. 1, no. 1, pp. 1-17, 2005.

[3] R. El Habbani, A. Chaqroune, T. Sqalli Houssaini et al., "Étude épidémiologique sur les calculs urinaires dans la région de Fès et sur le risque de récidive," Progrès en Urologie, vol. 26, no. 5, pp. 287-294, 2016.

[4] M. El Khebir, O. Fougeras, C. Le Gall et al., "Updating 2008 of 8th Conference of consensus of the French Society of medical emergencies of 1999. The treatment of adult renal colic by the emergency services and in ER," Progrès en Urologie, vol. 19, no. 7, pp. 462-473, 2009.

[5] A. Hesse, E. Brändle, D. Wilbert, K.-U. Köhrmann, and P. Alken, "Study on the prevalence and incidence of urolithiasis in Germany comparing the years 1979 vs. 2000," European Urology, vol. 44, no. 6, pp. 709-713, 2003.

[6] K. K. Stamatelou, M. E. Francis, C. A. Jones, L. M. Nyberg, and G. C. Curhan, "Time trends in reported prevalence of kidney stones in the United States: 1976-19941," Kidney International, vol. 63, no. 5, pp. 1817-1823, 2003.

[7] M. Daudon, P. Jungers, and B. Lacour, "Intérêt clinique de l'étude de la cristallurie," Annales de Biologie Clinique, vol. 62, pp. 379-393, 2004.

[8] M. Daudon, "La cristallurie: un marqueur diagnostique et pronostique des pathologies cristallogènes et des lithiases rénales," Revue Francophone des Laboratoires, vol. 2013, no. 455, pp. 67-73, 2013.

[9] M. Daudon, E. Letavernier, V. Frochot, J.-P. Haymann, D. Bazin, and P. Jungers, "Respective influence of calcium and oxalate urine concentration on the formation of calcium oxalate monohydrate or dihydrate crystals," Comptes Rendus Chimie, vol. 19, no. 11-12, pp. 1504-1513, 2016.

[10] C. F. Verkoelen, J. C. Romijn, W. C. De Bruijn, E. R. Boevé, L.-C. Cao, and F. H. Schröder, "Association of calcium oxalate monohydrate crystals with MDCK cells," Kidney International, vol. 48, no. 1, pp. 129-138, 1995.

[11] J. A. Wesson, E. M. Worcester, J. H. Wiessner, N. S. Mandel, and J. G. Kleinman, "Control of calcium oxalate crystal structure and cell adherence by urinary macromolecules," Kidney International, vol. 53, no. 4, pp. 952-957, 1998.

[12] M. Daudon, O. Traxer, E. Lechevallier, and C. Saussine, "La lithogenèse," Progrès en Urologie, vol. 18, no. 12, pp. 815-827, 2008.

[13] D. R. Basavaraj, C. S. Biyani, A. J. Browning, and J. J. Cartledge, "The role of urinary kidney stone inhibitors and promoters in the pathogenesis of calcium containing renal stones," EAU-EBU Update Series, vol. 5, no. 3, pp. 126-136, 2007.

[14] N. L. Miller, A. P. Evan, and J. E. Lingeman, "Pathogenesis of renal calculi," Urologic Clinics of North America, vol. 34, no. 3, pp. 295-313, 2007.

[15] A. P. Evan, F. L. Coe, J. E. Lingeman et al., "Mechanism of formation of human calcium oxalate renal stones on randall's plaque," The Anatomical Record: Advances in Integrative Anatomy and Evolutionary Biology, vol. 290, no. 10, pp. 1315-1323, 2007.

[16] D. J. Kok, S. E. Papapoulos, and O. L. M. Bijvoet, "Crystal agglomeration is a major element in calcium oxalate urinary stone formation," Kidney International, vol. 37, no. 1, pp. 51-56, 1990.

[17] S. Ahmed, M. M. Hasan, H. Khan, Z. A. Mahmood, and S. Patel, "The mechanistic insight of polyphenols in calcium oxalate urolithiasis mitigation," Biomedicine \& Pharmacotherapy, vol. 106, pp. 1292-1299, 2018.

[18] J. M. Fasano and S. R. Khan, "Intratubular crystallization of calcium oxalate in the presence of membrane vesicles: an in vitro study," Kidney International, vol. 59, no. 1, pp. 169-178, 2001.

[19] R. V. Bandeira Reidel, P. L. Cioni, and L. Pistelli, "Volatiles from different plant parts of Punica granatum grown in Tuscany (Italy)," Scientia Horticulturae, vol. 231, pp. 49-55, 2018.

[20] E. H. Endo, D. A. Garcia Cortez, T. Ueda-Nakamura, C. V. Nakamura, and B. P. Dias Filho, "Potent antifungal activity of extracts and pure compound isolated from pomegranate peels and synergism with fluconazole against Candida albicans," Research in Microbiology, vol. 161, no. 7, pp. 534-540, 2010.

[21] E. Stover and E. W. Mercure, “The pomegranate: a new look at the fruit of paradise," HortScience, vol. 42, no. 5, pp. 10881092, 2007. 
[22] V. Brighenti, S. F. Groothuis, F. P. Prencipe et al., "Metabolite fingerprinting of punica granatum 1. (pomegranate) polyphenols by means of high-performance liquid chromatography with diode array and electrospray ionization-mass spectrometry detection," Journal of Chromatography a, vol. 1480, pp. 20-31, 2016.

[23] E. P. Lansky and R. A. Newman, "Punica granatum (pomegranate) and its potential for prevention and treatment of inflammation and cancer," Journal of Ethnopharmacology, vol. 109, no. 2, pp. 177-206, 2007.

[24] A. Kumari, J. Dora, A. Kumar, and A. Kumar, "Pomegranate (Punica granatum)-overview," International Journal of Pharmaceutical and Chemical Sciences, vol. 1, no. 4, pp. 1218-1222, 2012.

[25] P. Ambigaipalan, A. C. De Camargo, and F. Shahidi, "Phenolic compounds of pomegranate byproducts (outer skin, mesocarp, divider membrane) and their antioxidant activities," Journal of Agricultural and Food Chemistry, vol. 64, no. 34, pp. 6584-6604, 2016.

[26] C. Castro-López, J. M. Ventura-Sobrevilla, M. D. GonzálezHernández et al., "Impact of extraction techniques on antioxidant capacities and phytochemical composition of polyphenol-rich extracts," Food Chemistry, vol. 237, pp. 1139-1148, 2017.

[27] P. Mena, L. Calani, C. Dall'Asta et al., "Rapid and comprehensive evaluation of (poly)phenolic compounds in pomegranate (Punica granatum L.) juice by UHPLC-MSn," Molecules, vol. 17, no. 12, pp. 14821-14840, 2012.

[28] M. Russo, C. Fanali, G. Tripodo et al., "Analysis of phenolic compounds in different parts of pomegranate (Punica granatum) fruit by HPLC-PDA-ESI/MS and evaluation of their antioxidant activity: application to different Italian varieties," Analytical and Bioanalytical Chemistry, vol. 410, no. 15, pp. 3507-3520, 2018.

[29] Z. Amri, F. Zaouay, H. Lazreg-Aref et al., "Phytochemical content, fatty acids composition and antioxidant potential of different pomegranate parts: comparison between edible and non edible varieties grown in Tunisia," International Journal of Biological Macromolecules, vol. 104, pp. 274-280, 2017.

[30] P. Lucci, D. Pacetti, M. R. Loizzo, and N. G. Frega, "Punica granatum cv. dente di cavallo seed ethanolic extract: antioxidant and antiproliferative activities," Food Chemistry, vol. 167, pp. 475-483, 2015.

[31] F. Afaq, M. Saleem, C. G. Krueger, J. D. Reed, and H. Mukhtar, "Anthocyanin- and hydrolyzable tannin-rich pomegranate fruit extract modulates MAPK and NF-?B pathways and inhibits skin tumorigenesis in CD-1 mice," International Journal of Cancer, vol. 113, no. 3, pp. 423-433, 2005.

[32] M. N. Al-Muammar and F. Khan, "Obesity: the preventive role of the pomegranate (Punica granatum)," Nutrition, vol. 28, no. 6, pp. 595-604, 2012.

[33] S. Akter, A. Sarker, and M. S. Hossain, "Antidiarrhoeal activity of rind of Punica granatum," International Current Pharmaceutical Journal, vol. 2, no. 5, pp. 101-104, 2013.

[34] L. M. Ferreira, M. H. M. Sari, V. F. Cervi et al., "Pomegranate seed oil nanoemulsions improve the photostability and in vivo antinociceptive effect of a non-steroidal anti-inflammatory drug," Colloids and Surfaces B: Biointerfaces, vol. 144, pp. 214-221, 2016.

[35] I. Hmid, H. Hanine, D. Elothmani, and A. Oukabli, "The physico-chemical characteristics of Morrocan pomegranate and evaluation of the antioxidant activity for their juices,"
Journal of the Saudi Society of Agricultural Sciences, vol. 17, no. 3, pp. 302-309, 2018.

[36] S. Lairini, R. Bouslamti, F. Zerrouq, and A. Farah, "Valorisation de l'extrait aqueux de l'écorce de fruit de punica granatum par l'étude de ses activités antimicrobienne et antioxydante," Journal of Materials and Environmental Science, vol. 5, pp. 2314-2318, 2014.

[37] Y. Li, T. Ye, F. Yang et al., "Punica granatum (pomegranate) peel extract exerts potent antitumor and anti-metastasis activity in thyroid cancer," RSC Advances, vol. 6, no. 87, pp. 84523-84535, 2016.

[38] S. Subash, M. M. Essa, A. Al-Asmi et al., "Pomegranate from Oman alleviates the brain oxidative damage in transgenic mouse model of alzheimer's disease," Journal of Traditional and Complementary Medicine, vol. 4, no. 4, pp. 232-238, 2014.

[39] A. E. Abdel Moneim, "Evaluating the potential role of pomegranate peel in aluminum-induced oxidative stress and histopathological alterations in brain of female rats," Biological Trace Element Research, vol. 150, no. 1-3, pp. 328-336, 2012.

[40] W. A. Al-Megrin, "In vivo study of pomegranate (Punica granatum) peel extract efficacy against Giardia lamblia in infected experimental mice," Asian Pacific Journal of Tropical Biomedicine, vol. 7, no. 1, pp. 59-63, 2017.

[41] R. Kachkoul, T. Sqalli Houssaini, R. El Habbani et al., "Phytochemical screening and inhibitory activity of oxalocalcic crystallization of Arbutus unedo L. leaves," Heliyon, vol. 4, no. 12, Article ID e01011, 2018.

[42] S. Feknous, F. Saidi, and R. M. Said, "Extraction , caractérisation et identification de quelques métabolites secondaires actifs de la mélisse (Melissa officinalis L.)," Nature \& Technology, vol. 11, pp. 7-13, 2014.

[43] M. Virot, V. Tomao, C. Ginies, F. Visinoni, and F. Chemat, "Green procedure with a green solvent for fats and oils" determination," Journal of Chromatography A, vol. 1196-1197, pp. 147-152, 2008.

[44] A. Jiménez-Zamora, C. Delgado-Andrade, and J. A. RufiánHenares, "Antioxidant capacity, total phenols and color profile during the storage of selected plants used for infusion," Food Chemistry, vol. 199, pp. 339-346, 2016.

[45] R. Kachkoul, T. Squalli Housseini, M. Mohim, R. El Habbani, Y. Miyah, and A. Lahrichi, "Chemical compounds as well as antioxidant and litholytic activities of Arbutus unedo L. leaves against calcium oxalate stones," Journal of Integrative Medicine, vol. 17, no. 6, pp. 430-437, 2019.

[46] R. María, M. Shirley, C. Xavier et al., "Preliminary phytochemical screening, total phenolic content and antibacterial activity of thirteen native species from Guayas province Ecuador," Journal of King Saud University-Science, vol. 30, no. 4, pp. 500-505, 2018.

[47] E. Iqbal, K. A. Salim, and L. B. L. Lim, "Phytochemical screening, total phenolics and antioxidant activities of bark and leaf extracts of Goniothalamus velutinus (Airy Shaw) from Brunei Darussalam," Journal of King Saud University-Science, vol. 27, no. 3, pp. 224-232, 2015.

[48] F. M. Awah, P. N. Uzoegwu, P. Ifeonu et al., "Free radical scavenging activity, phenolic contents and cytotoxicity of selected Nigerian medicinal plants," Food Chemistry, vol. 131, no. 4, pp. 1279-1286, 2012.

[49] F. S. Hosseinian, W. Li, and T. Beta, "Measurement of anthocyanins and other phytochemicals in purple wheat," Food Chemistry, vol. 109, no. 4, pp. 916-924, 2008.

[50] F. M. Bhat and C. S. Riar, "Characterizing the pigmented traditional rice cultivars grown in temperate regions of 
Kashmir (India) for free and bound phenolics compounds and in vitro antioxidant properties," Journal of Cereal Science, vol. 76, pp. 253-262, 2017.

[51] H. Wang, X. D. Gao, G. C. Zhou, L. Cai, and W. B. Yao, "In vitro and in vivo antioxidant activity of aqueous extract from Choerospondias axillaris fruit," Food Chemistry, vol. 106, no. 3, pp. 888-895, 2008.

[52] M. Oyaizu, "Studies on products of browning reaction. Antioxidative activities of products of browning reaction prepared from glucosamine," The Japanese Journal of $\mathrm{Nu}$ trition and Dietetics, vol. 44, no. 6, pp. 307-315, 1986.

[53] M. Oktay, İ. Gülçin, and Ö and Küfrevioğlu, "Determination of in vitro antioxidant activity of fennel (Foeniculum vulgare) seed extracts," LWT-Food Science and Technology, vol. 36, no. 2, pp. 263-271, 2003.

[54] B. Hess, U. Meinhardt, L. Zipperle, R. Giovanoli, and P. Jaeger, "Simultaneous measurements of calcium oxalate crystal nucleation and aggregation: impact of various modifiers," Urological Research, vol. 23, no. 4, pp. 231-238, 1995.

[55] R. Kachkoul, T. Sqalli Houssaini, Y. Miyah, M. Mohim, R. El Habbani, and A. Lahrichi, "The study of the inhibitory effect of calcium oxalate monohydrate's crystallization by two medicinal and aromatic plants: Ammi visnaga and Punica granatum," Progrès en Urologie, vol. 28, no. 3, pp. 156-165, 2018.

[56] B. Hess, S. Jordi, L. Zipperle, E. Ettinger, and R. Giovanoli, "Citrate determines calcium oxalate crystallization kinetics and crystal morphology-studies in the presence of tammhorsfall protein of a healthy subject and a severely recurrent calcium stone former," Nephrology Dialysis Transplantation, vol. 15 , no. 3, pp. 366-374, 2000.

[57] F. Romeo, G. Ballistreri, S. Fabroni et al., "Chemical characterization of different sumac and pomegranate extracts effective against Botrytis cinerea Rots," Molecules, vol. 20, no. 7, pp. 11941-11958, 2015.

[58] Z. Derakhshan, M. Ferrante, M. Tadi et al., "Antioxidant activity and total phenolic content of ethanolic extract of pomegranate peels, juice and seeds," Food and Chemical Toxicology, vol. 114, pp. 108-111, 2018.

[59] S. Kharchoufi, F. Licciardello, L. Siracusa, G. Muratore, M. Hamdi, and C. Restuccia, "Antimicrobial and antioxidant features of "Gabsi" pomegranate peel extracts," Industrial Crops and Products, vol. 111, pp. 345-352, 2018.

[60] E. Sentandreu, M. Cerdán-Calero, and J. M. Sendra, "Phenolic profile characterization of pomegranate (Punica granatum) juice by high-performance liquid chromatography with diode array detection coupled to an electrospray ion trap mass analyzer," Journal of Food Composition and Analysis, vol. 30, no. 1, pp. 32-40, 2013.

[61] M. Zahin, F. Aqil, and I. Ahmad, "Broad spectrum antimutagenic activity of antioxidant active fraction of Punica granatum L. peel extracts," Mutation Research/Genetic Toxicology and Environmental Mutagenesis, vol. 703, no. 2, pp. 99-107, 2010.

[62] U. A. Fischer, R. Carle, and D. R. Kammerer, "Identification and quantification of phenolic compounds from pomegranate (Punica granatum L.) peel, mesocarp, aril and differently produced juices by HPLC-DAD-ESI/MSn," Food Chemistry, vol. 127, no. 2, pp. 807-821, 2011.

[63] C.-L. Chan, R.-Y. Gan, N. P. Shah, and H. Corke, "Enhancing antioxidant capacity of Lactobacillus acidophilus-fermented milk fortified with pomegranate peel extracts," Food Bioscience, vol. 26, pp. 185-192, 2018.
[64] M. Abid, H. Yaich, S. Cheikhrouhou et al., "Antioxidant properties and phenolic profile characterization by LC-MS/ MS of selected Tunisian pomegranate peels," Journal of Food Science and Technology, vol. 54, no. 9, pp. 2890-2901, 2017.

[65] A. M. Gómez-Caravaca, V. Verardo, M. Toselli, A. SeguraCarretero, A. Fernández-Gutiérrez, and M. F. Caboni, "Determination of the major phenolic compounds in pomegranate juices by HPLC-DAD-ESI-MS," Journal of Agricultural and Food Chemistry, vol. 61, no. 22, pp. 53285337, 2013.

[66] E. M. C. Alexandre, S. Silva, S. A. O. Santos et al., “Antimicrobial activity of pomegranate peel extracts performed by high pressure and enzymatic assisted extraction," Food Research International, vol. 115, pp. 167-176, 2019.

[67] K. Šavikin, J. Živković, A. Alimpić et al., "Activity guided fractionation of pomegranate extract and its antioxidant, antidiabetic and antineurodegenerative properties," Industrial Crops and Products, vol. 113, pp. 142-149, 2018.

[68] C. Pagliarulo, V. De Vito, G. Picariello et al., "Inhibitory effect of pomegranate (Punica granatum L.) polyphenol extracts on the bacterial growth and survival of clinical isolates of pathogenic Staphylococcus aureus and Escherichia coli," Food Chemistry, vol. 190, pp. 824-831, 2016.

[69] P. Aguilar-Zárate, J. E. Wong-Paz, M. Michel et al., "Characterisation of pomegranate-husk polyphenols and semipreparative fractionation of punicalagin," Phytochemical Analysis, vol. 28, no. 5, pp. 433-438, 2017.

[70] D. Sharma, Y. N. Dey, I. Sikarwar, R. Sijoria, M. M. Wanjari, and A. D. Jadhav, "In vitro study of aqueous leaf extract of Chenopodium album for inhibition of calcium oxalate and brushite crystallization," Egyptian Journal of Basic and Applied Sciences, vol. 3, no. 2, pp. 164-171, 2016.

[71] A. Noorafshan, S. Karbalay-Doust, and F. Karimi, "Diosmin reduces calcium oxalate deposition and tissue degeneration in nephrolithiasis in rats: a stereological study," Korean Journal of Urology, vol. 54, no. 4, pp. 252-257, 2013.

[72] T. H.-S. Hsu, S.-Y. Lin, C.-C. Lin, and W.-T. Cheng, "Preliminary feasibility study of FTIR microscopic mapping system for the rapid detection of the composited components of prostatic calculi," Urological Research, vol. 39, no. 3, pp. 165-170, 2011.

[73] J.-M. Ouyang, H. Zheng, and S.-P. Deng, "Simultaneous formation of calcium oxalate (mono-, di-, and trihydrate) induced by potassium tartrate in gelatinous system," Journal of Crystal Growth, vol. 293, no. 1, pp. 118-123, 2006.

[74] C. Conti, M. Casati, C. Colombo et al., "Synthesis of calcium oxalate trihydrate: new data by vibrational spectroscopy and synchrotron X-ray diffraction," Spectrochimica Acta Part A: Molecular and Biomolecular Spectroscopy, vol. 150, pp. 721730, 2015.

[75] J.-M. Ouyang, S.-P. Deng, N. Zhou, and B. Tieke, "Effect of tartrates with various counterions on the precipitation of calcium oxalate in vesicle solutions," Colloids and Surfaces A: Physicochemical and Engineering Aspects, vol. 256, no. 1, pp. 21-27, 2005.

[76] J.-M. Ouyang, N. Zhou, L. Duan, and B. Tieke, "Ability of multifunctional sodium carboxylates to favor crystal growth of calcium oxalate dihydrate and trihydrate in lecithin-water liposome systems," Colloids and Surfaces A: Physicochemical and Engineering Aspects, vol. 245, no. 1-3, pp. 153-162, 2004.

[77] X.-Q. Yao, J.-M. Ouyang, H. Peng, W.-Y. Zhu, and H.-Q. Chen, "Inhibition on calcium oxalate crystallization and repair on injured renal epithelial cells of degraded 
soybean polysaccharide," Carbohydrate Polymers, vol. 90, no. 1, pp. 392-398, 2012.

[78] Y. Zhang, Y. Tang, J. Xu, D. Zhang, G. Lu, and W. Jing, "Modulation of polyepoxysuccinic acid on crystallization of calcium oxalate," Journal of Solid State Chemistry, vol. 231, pp. 7-12, 2015.

[79] J.-M. Ouyang, L. Duan, and B. Tieke, "Effects of carboxylic acids on the crystal growth of calcium oxalate nanoparticles in lecithin-water liposome systems," Langmuir, vol. 19, no. 21, pp. 8980-8985, 2003.

[80] A. Mokrani and K. Madani, "Effect of solvent, time and temperature on the extraction of phenolic compounds and antioxidant capacity of peach (Prunus persica L.) fruit," Separation and Purification Technology, vol. 162, pp. 68-76, 2016. 